Jurnal Islamika: Jurnal Ilmu-Ilmu Keislaman p-ISSN:1693-8712 | e-ISSN: 2502-7565

Vol 19, No 01, Juli 2019, pp. 46-57

\title{
Pendidikan Akhlak Ibnu Miskawaih
}

\section{Indah Herningrum ${ }^{1}$, Muhammad Alfian ${ }^{2}$}

${ }^{1,2}$ Institut Agama Islam Negeri (IAIN) Kerinci

e-mail: Indah.hotmail@gmail.com, Fiyan.uin1@gmail.com

\begin{abstract}
Ibn Makawaih is a philosopher who focuses on morals. Ibn Miskawaih states that morality is a state of the soul of a person who encourages to do something without going through consideration of thoughts first. The purpose of moral education formulated by Ibn Miskawaih is the realization of an inner attitude that is able to encourage spontaneously to give birth to all good-value actions so that they can achieve perfection and obtain true and perfect happiness. There are three important things that can be understood as moral education material, namely: things that are obligatory for the needs of the human body, things that are obligatory for the soul and things that are obligatory for their relationship with fellow human beings. Ibn Miskawaib in his character concept emphasizes psychological and religious aspects to improve the quality of one's character.
\end{abstract}

Key Word: Moral Education, Ibnu Miskawaih

Abstrak: Ibnu Miskawaih merupkan seorang filosof yang menjadikan akhlak sebagai focus perhatiannya memusatkan perhatiannya terhadap akhlak. Ibnu Miskawaih menyatakan bahwa Akhlak adalah keadaan jiwa seseorang yang mendorong untuk melakukan sesuatu perbuatan tanpa melalui pertimbangan fikiran terlebih dahulu. Tujuan pendidikan akhlak yang dirumuskan oleh Ibnu Miskawaih adalah terwujudnya sikap batin yang mampu mendorong secara spontan untuk melahirkan semua perbuatan yang bernilai baik sehingga dapat mencapai kesempurnaan dan memperoleh kebahagiaan sejati dan sempurna.Ada tiga hal penting atau pokok yang dapat dipahami sebagai materi pendidikan akhlaknya, yaitu: hal-hal yang wajib bagi kebutuhan tubuh manusia, hal-hal yang wajib bagi jiwa dan hal-hal yang wajib bagi hubungannya dengan sesama manusia. Ibnu Miskawaih dalam konsep akhlaknya menekankan aspek kejiwaan dan agama untuk meningkatkan kualitas akhlak seseorang.

Kata kunci: Pendidikan Akhlak, Ibnu Miskawaih 


\section{PENDAHULUAN}

Salah satu misi agama Islam adalah untuk menyempurnakan akhlak manusia. Akhlak al karimah yang diajarkan dalam Islam merupakan orientasi yang harus dipegang oleh setiap muslim. Seorang yang hendak memperoleh kebahagiaan yang sejati (al-sa'adah al-haqiqiyah), hendaknya menjadikan akhlak sebagai landasanya dalam bertindak dan berperilaku. Sebaliknya, orang yang tidak memperdulikan pembinaan akhlak adalah orang yang tidak memiliki arti dan tujuan hidup.

Di era globalisasi seperti sekarang ini, sedikitnya terdapat tiga fungsi akhlak dalam kehidupan manusia. Pertama, ia dapat dijadikan sebagai panduan dalam memilih apa yang di ubah, dan apa pula yang harus dipertahankan; kedua, dapat dijadikan sebagai obat penawar dalam menghadapi berbagai ideologi kontemporer, berbagai jerat hedonis yang menjadi ciri negatif era globalisasi, dan ketiga, dapat pula di jadikan sebagai benteng dalam menghadapi perilaku menyimpang akibat pengaruh negatif globalisasi. ${ }^{1}$

Ibnu Miskawaih adalah seorang filosof muslim yang paling banyak mengkaji dan mengungkapkan persoalan akhlak. Ibnu Miskawaih mendasarkan perinsip keutamaan moralnya kepada teori "pertengahan" (al-wasth). Menurutnya, sebuah tindakan dikatakan benar bila dia ditengah ekstrim kelebihan dan ekstrim kekurangan sehingga seorang dapat di sebut adil bila ia mampu menempatkan dirinya diantara aniaya dan teraniaya.

\section{PEMBAHASAN}

\section{Riwayat Hidup Latar Belakang Pendidikan dan Karya-karya Ibn Miskawaih}

1. Riwayat Hidup Ibn Miskawaih

Ibn Miskawaih adalah seorang filosof muslim yang menitik beratkan perhatiannya pada Etika Islam. Nama lengkapnya adalah Abu Ali Ahmad Ibn Muhammad Ibn Miskawaih. Lahir di Ray, menetap di Isfahan, Iran, dan meninggal dunia di kota tersebut pada tahun 421 Hijri, bertepatan dengan tahun 1030 Masehi, pada tanggal 9 Shafar 421 H / 16 Februari 1030 M. Mengenai tahun kelahiranya masih dalam ketidak pastian. Margoliouth menyebutkan tahun 330 H / 932 M. sedangkan Abdul Azis Izzat menyebutkan tahun 325 H. ${ }^{2}$

2. Riwayat Pendidikan Ibn Miskawaih

Riwayat pendidikan Ibn Miskawaih tidak diketahui secara jelas. Ibn Miskawaih tidak menuliskan otobiografinya, dan para penulis riwayat hidupnya pun tidak memberikan gambaran yang jelas mengenai riwayat pendidikan Ibn Miskawaih. ${ }^{3}$ Dengan demikian dapat

\footnotetext{
${ }^{1}$ Franz Magniz Suseno. 1987. Etika Dasar: maslah-maslah pokok filsafat moral. Yogyakarta: Kanasil. hal. 15.

2 A.A. Izzat dalam Ahmad Azhar Basyir. 1983. Miskawaib: Riwayat Hidup dan Pemikiran Filsafatnya,Yogyakarta: Nur Cahaya. hal. 1.

${ }^{3}$ Ahmad Azhar Basyir. 1983. Miskawaih: Riwayat Hidup dan Pemikiran Filsafatnya. hal. 3.
} 
diduga bahwa Ibn Miskawaih juga tidak berbeda dengan kebiasaan anak pada umumnya untuk menuntut ilmu pada masanya.

Ahmad Amin mengatakan, gambaran pendidikan anak pada zaman 'Abbasiyah pada umumnya bermula dengan belajar membaca, menulis, mempelajari al-Qur'an, dasar-dasar bahasa Arab, tata bahasa Arab (Nahwu) dan 'Arudh (ilmu membaca dan menyair). Mata pelajaran tersebut diberikan di surau-surau, sedangakan pada kalangan keluarga yang berada, guru didatangkan ke rumah untuk memberikan les privat kepada anak-anaknya. ${ }^{4}$

Tahap berikutnya setelah ilmu dasar tersebut diselesaikan adalah memberi pelajaran ilmu fiqh, hadist, sejarah, (khususnya sejarah Arab, Persi, dan India) dan matematika. Selain itu diberikan pula macam-macam ilmu praktis seperti; musik, main catur, dan furusiah (semacam ilmu kemiliteran). ${ }^{5}$

Diduga Ibnu Miskawaih pun mengalami pendidikan semacam itu pada masa mudanya, meskipun menurut dugaan juga Ibn Miskawaih tidak mengikuti pelajaran privat, karena latar belakang ekonomi keluarganya yang kurang mampu untuk mendatangkan guru privat, terutama untuk pelajaran-pelajaran lanjutan yang memerlukan biaya mahal. ${ }^{6}$

Karir akademisnya diawali dengan menimba ilmu pengetahuan di Baghdad dalam bidang sastra. Banyak cabang ilmu pengetahuan dan filsafat yang di pelajari Ibn Miskawaih, tetapi Ibn Miskawaih lebih memusatkan perhatiannya pada bidang sejarah dan etika. ${ }^{7}$ Ibn Miskawaih belajar sejarah, terutama Târîkh al-Tabarî (Sejarah yang ditulis Imam al-Tabari), pada Abu Bakar Ahmad bin Kamil al-Qadi pada tahun 350 H/960 M. Sementara ilmu filsafatnya didapat dari Ibnu al-Khammar, yaitu seorang mufassir kenamaan dan salah seorang pensyarah karangan-karangan Aristoteles. Ibn Miskawaih mengkaji ilmu kimia bersama Abu al-Thayyib al-Razi, seorang ahli kimia, dari beberapa pernyataan ibn sina dan al-Tauhidi, tampak bahwa mereka berpendapat bahwa ia tidak mampu berfilsafat. Namun, M. Iqbal, menanggapi sebaliknya. Iqbal mengatakan bahwa al-miskawaih merupakan salah satu pemikir teistis, moralis dan sejarawan parsi paling terkenal. ${ }^{8}$

Pengetahuan Ibn Miskawaih yang sangat menonjol diperoleh dari hasil membaca buku tentang sejarah, filsafat, dan sastra. ${ }^{9}$ Hingga saat ini nama Ibn Miskawaih sangat dikenal terutama dalam keahliannya sebagai sejarahwan dan filsuf. Sebagai filsuf, Ibn Miskawaih

\footnotetext{
${ }^{4}$ Ahmad Amin dalam Ahmad Azhar Basyir. 1983. Miskawaib: Riwayat Hidup dan Pemikiran Filsafatnya. hal. 3. ${ }^{5}$ Ibid, hal. 3.

'Ibid, hal. 3-4.

7 Taufik Abdullah, et. Al. 2000. Ensiklopedi Islam. Jakarta: PT. Ichtiar Baru Van Hoeve, jil. 3, cet. VIII,

${ }^{8}$ M. Iqbal. 1992.the development of metaphysics in Persia. hlm. 26 (dalam M. M. syarif, para filosof muslim, Bandung:

${ }^{9}$ Ibid.
} hal.195. penerbit Mizan, hal. 84. 
dikenal sebagai Bapak Etika Islam. Ibn Miskawaih-lah filsuf Islam yang mula-mula secara lengkap mengemukakan teori etikanya, dan menulis buku-buku yang membahas tentang etika.

3. Karya-karya Ibn Miskawaih

Sebagai seorang pemikir muslim yang produktif, Ibn Miskawaih telah menulis bukubuku dalam berbagai macam bidang keahliannya, tetapi hanya sebagian kecil dari karyanya yang sekarang masih ada dan dikenal oleh masyarakat. ${ }^{10}$ Karya-karya Ibn Miskawaih hampir semuanya tidak luput dari kepentingan filsafat Etika, sehubungan dengan hal tersebut tidak mengherankan jika Ibn Miskawaih dikenal sebagai seorang moralis. ${ }^{11}$

Terlepas dari semua itu, Ibn Miskawaih merupakan sosok filosof Muslim yang berhasil. Keberhasilan Ibn Miskawaih dibuktikan dengan banyaknya buku yang telah ditulisnya. Yaqut dalam Abdurrahman Badawi memberikan daftar 13 buku yang dikaitkan dengan Ibn Miskawaih, di antaranya:

1) Al-Fawz al-Akbar.

2) Al-Fawz al-Asghar.

3) Tajârib al-Umam (sejarah dari Air Bah 369/979).

4) Uns al-Farîd (kumpulan anekdot, ayat, maksim, dan peribahasa).

5) Tartîb al-Sa'âdab (tentang etika dan politik).

6) Al-Mustaufâ (ayat dipilih).

7) Jawidan Khirâd (koleksi maksim kebijaksanaan).

8) Al-Jâmi'

9) Al-Siyâr (pada perilaku hidup).

Ibn Miskawaih pada dasarnya adalah ahli sejarah dan moralis. Selain itu Ibn Miskawaih adalah seorang penyair. Abdurrahman Badawi mengatakan, di samping sebagai sejarawan dan moralis, Ibn Miskawaih juga merupakan salah satu penyair atau sastrawan. ${ }^{12}$ Salah satu bukti yang tidak terbantahkan dari pandangan Badawi di atas adalah karya-karya Ibn Miskawaih yang juga terdapat dalam bentuk kumpulan-kumpulan puisi atau sya'ir.

Bagian terpenting dalam kegiatan filosofis Ibn Miskawaih didedikasikan untuk etika. Ibn Miskawaih adalah seorang moralis dalam arti sebenarnya. Tiga buku yang terpenting dalam pembahasannya mengenai etika telah sampai pada masyarakat, yaitu: (1)Tartîb asSa'âdah, (2) Tahdð̨̧̨ al-Akblâq, dan (3)Jawidan Khirad.

\footnotetext{
10 Taufik Abdullah et. al.2000. Ensiklopedi Islam. hal. 89.

11 Abudin Nata. 2003. Pemikiran Para Tokoh Pendidikan Islam, Seri Kajian Filsafat Pendidikan Islam. Jakarta: Raja Grafindo Persada. cet. III, hal. 6.

${ }^{12}$ Ibid, hal. 470-471.
} 
Selain di bidang etika, Ibn Miskawaih juga memiliki berbagai perhatian dan kontribusi lain: Digambarkan pada periode tertentu dalam kehidupannya, Ibn Miskawaih aktif menuntut alkemi; ahli biografi, filosof, dan orang arif. ${ }^{13}$

Ibn Miskawaih menempati posisi sentral dalam tradisi etika filosofis Muslim. Di satu pihak, Ibn Miskawaih mengikhtisarkan dan menjelaskan dengan cara yang baik sekali elemen-elemen pokok dari bagian "filsafat praktis" ini sebagaimana dikenal dunia Muslim hingga masanya, dan di pihak lain, Ibn Miskawaih mempunyai pengaruh penting pada ahliahli etika Muslim mazhab lain. ${ }^{14}$

Pengaruhnya yang paling jelas terlihat dalam literatur filosofiko-etika Persia akhir, khususnya dalam Akblâq Nashiri karya Nashir Al-Din Thusi (672 Hijri/1274 Masehi), yang porsi-porsi utamanya diambil dari Tahdz̨îh, dan dalam Akblâq Jalali karya Jalal Al-Din AlDawwani (908 Hijri/1502 Masehi) yang pada gilirannya tergantung pada karya Al-Thusi. Di antara yang kedua yang pada karya-karya etika Abu Hamid Al-Ghazali (505 Hijri/1111 Masehi) khususnya pada karya Ibyâ' Ulûm Al-Dîn (Menghidupkan kembali Ilmu-ilmu Agama), karena melalui Al-Ghazali, teolog Islam besar, inilah elemen-elemen filosofiko-etika ini masuk kedalam tradisi religius yang mendominasi pemikiran sunni terkemudian ini. ${ }^{15}$

Terlepas dari pengaruh di atas, dengan membaca secara cermat Tahd₹î́b dan membandingkannya dengan tulisan-tulisan Muslim lainnya tentang etika, maka akan cinderung mendukung penilaian T.J. De Boer:

“...dan bagaimanapun juga kita bukan saja patut memuji secara umum upayanya untuk memberikan suatu system etika yang barus bersib dari casuistry (penilaian tentang baik dan buruk dengan cara merujuk ke teori, konvensi sosial, dan sebagainya) kaum moralis dan asketisisme kaum sufi, tetapi juga patut mengakui dalam pelaksanaan maksudnya itu adanya rasa yang baik dari seseorang yang luas kulturnya." 16

\section{Konsep Manusia}

1. Manusia

Manusia dalam pandangan Ibnu Miskawaih adalah makhluk yang mempunyai aktivitas yang khas, yang tidak dimiliki oleh makhluk lain yang ada pada muka bumi ini. Manusia merupakan benda alam yang paling mulia dan juga sempurna. Lebih lanjut, Ibnu Miskawaih

13 Menurut Al-Qifthi (646 Hijri/1248 Masehi) dan ahli Biografi para dokter, Ibn Abi Ushay bi'ah (668 Hijri/1270 Masehi), menganggap berbagai risalah medis ditulis olehnya. Dalam Tahdž̂́b Ibn Miskawaih menyebutkan bahwa dirinya menulis sebuah ikhtisar tentang ilmu aritmatika, dan akhirnya ahli sejarah sastra yaitu Al-Tsa'álibi (429) Hijri/1038) menyebutkan bahwa Ibn Miskawaih berada "dipuncak keunggulan, baik literatur, retorika maupun puisi" dan mencatat beberapa puisi Ibn Miskawaih dalam antologinya. Al-Qifthi dalam Ibn Miskawaih, Menuju Kesempurnaan Akblak: Buku Dasar Pertama Tentang Filsafat Etika, terj. Helmi Hidayat, hal. 20.

${ }^{14}$ Ibid, hal 22.

${ }^{15}$ Ibid, hal. 22

${ }^{16}$ T.J. De Boer dalam Ibn Miskawaih. 1994. Menuju Kesempurnaan Akhlak: Buku Dasar Pertama Tentang Filsafat Etika, terj. Helmi Hidayat, hal. 22. 
mengatakan bahwa substansi manusia itu menjadi wujud karena kekuasaan Allah SWT. Sedangkan untuk membuat substansi manusia menjadi baik atau buruk diserahkan kepada manusia dan bergantung pada kehendaknya. ${ }^{17}$ Dengan demikian dalam konsep Ibnu Miskawaih beliau sangat besar perhatiannya terhadap akhlak atau yang populer disebut sebagai karakter. Beliau mengatakan bahwa pembinaan karakter dianggap sebagai bidang yang terbaik ketimbang bidang yang lain karena bidang pembinaan karakter difokuskan pada pengarahan tingkah laku manusia agar menjadi baik.

2. Manusia Sempurna

Ibnu Miskawaih menyebutkan bahwa manusia dipandang sebagai manusia sempurna karena dua hal yang dimilikinya, yaitu kognitif (teoritis) dan praktis. Kognitif yang dimaksud adalah kemampuan manusia untuk berpikir sehingga menghasilkan ilmu pengetahuan yang dengan ilmu pengetahuan tersebut persepsinya, wawasannya, dan kerangka berpikirnya pun menjadi akurat. Dengan demikian, manusia tidak akan ragu lagi dengan apa yang diyakininya. Sedangkan parktis adalah kemampuan manusia untuk mengorganisasikan berbagai hal, dalam bahasa lain Miskawaih menyebutnya sebagai kesempurnaan karakter. ${ }^{18}$

Kesempurnaan karakter dapat dicapai dengan mengelola aspek-aspek yang ada dalam diri manusia seperti berpikir (al-quwwah al-natiqab), nafsu syahwiyah, dan amarah (al-quwwah alghadabiyyah). Dengan demikian kesempurnaan karakter akan tercapai jika kedua aspek sebelumnya saling berkaitan dan saling menunjang karena kognitif (teori) adalah permulaannya dan praktis/perbuatan adalah akhirnya.

\section{Pemikiran Pendidikan}

Pemikiran Ibnu Miskawaih dalam hal pendidikan tidak bisa dilepas dari konsepnya tentang manusia dan akhlak. Berikut akan dikemukakan tentang dasar pemikiran (tingkat daya dan akhlak) dan konsep pendidikan (tujuan, materi, metode, lingkungan pendidikan dan kode etik pendidik dan peserta didik) mmenurut Ibnu Maskawaih.

1. Tingkatan Daya

Pandangan Ibnu Miskawaih terhadap manusia tidak jauh berbeda dengan pandangan filosof lainya. Menurutnya, di dalam diri manusia mempunyai 3 macam daya, yaitu (1) daya bernafsu (al-nafs al-bahimiyyah) sebagai daya paling rendah, (2) daya berani (al-nafs al-sabu'iyyah) sebagai daya pertengahan dan (3) daya berpikir (al-nafs al-nathiqah) sebagai daya tertinggi.

\footnotetext{
${ }^{17}$ IbnuMiskawaih. 1994. Menuju Kesempurnaan Akblak, terj. Tabdzib al-Akblak. Bandung: MIZAN. cet. I, hal.62.

${ }^{18}$ Ibid. hal. 63
} 
${ }^{19}$ ketiganya merupakan unsur ruhani manusia yang asal kejadianya berbeda antara satu dengan yang lainya.

Ibnu Miskawaih mengtakan bahwa hubungan jiwa al-babimiyyat/al-syahwiyyat (bernafsu) dan jiwa al-ghadabiyyat/al-sabu'iyyat (berani) dengan jasad pada hakikatnya saling memepengaruhi. Kuat atau lemahnya, sehat atau sakitnya tubuh berpengaruh terhadap kuat atau lemahnya, sehat atau sakitnya kedua macam jiwa tersebut. Oleh karena itu Ibnu Miskawaih melihat bahwa manusia terdiri dari unsur jasad dan ruhani yang saling berhubungan. ${ }^{20}$

2. Konsep akhlak

Pemikiran akhlak Ibnu Miskawaih banyak dipengaruhi oleh para filosof yunani, seperti Aristoteles, Plato, dan Galen dengan meramu pemikiran-pemikiran tersebut dengan ajaranajaran Islam. Di samping itu, Ibnu Miskawaih juga banyak dipengaruhi oleh para filosof muslim, seperti al-Kindi, al-Farabi dan al-Razi serta lainya. Oleh karena itu, corak pemikiran Ibnu Miskawaih dapat dikategorikan ke dalam tipologi etika filosofi (etika rasional), yaitu pemikiran etika yang banyak dipengaruhi oleh para filosof, terutama filosof yunani. ${ }^{21}$

Karakteristik pemikiran Ibnu Miskawaih dalam pendidikan akhlak secara umum dimulai dengan pembahasan tentang akhlak (karakter/watak). Menurutnya watak itu ada yang bersifat alami dan watak yang diperoleh melalui kebiasaan atau latihan. Kedua watak tersebut menurut Ibnu Miskawaih bahwa watak itu pada hakekatnya tidak alami, walaupun kita diciptakan dengan menerima watak, akan tetapi watak tersebut dapat diusahakan melalui pendidikan dan pengajaran. ${ }^{22}$

Selanjutnya, Ibnu Miskawaih juga menegaskan bahwa pendidikan akhlak didasarkan pada doktrin jalan tengah. ${ }^{23}$ Menurutnya jalan tengah diartikan dengan keseimbangan, moderat, harmoni, utama, mulia atau posisi tengah antara dua ekstrem baik dan buruk yang ada dalam jiwa manusia. Menurutnya, posisi tengah jiwa bahimiyah adalah iffah, yaitu menjaga diri dari perbuatan dosa dan maksiat.

Keempat keutamaan al fadhilah akhlak al-iffah, al-saja 'ah, al-hikmahdan al-adalah adalah merupakan pokok atau induk akhlak yang mulia. Adapun lawannya adaempat pulayaitu al-jah, as-syarh, al-jubn dan al-jur. ${ }^{24}$ Selanjutnya pemikiran IbnuMiskawaih tentang konsep/aspek pendidikan akhlak dapat dijelaskan sebagai berikut :

${ }^{19}$ Ibnu Miskawaih. Tabdzib al-Akblak wa Tathbir al-A'araq, (Beirut : Mansyurah Dar al-Maktabah al-Hayat, 1398 H), cet .II, hal. 62

${ }^{20}$ Ibid.,hal. 7-8

${ }^{21}$ Majid Fakhry. 1995. Etika Dalam Islam, terj. Zakiyuddin Baidhawy. Yogyakarta : Pustaka Peljar. hal. 22

${ }^{22}$ Ibnu Miskawaih, op.cit., hal. 25

${ }^{23}$ Abuddin Nata, op.cit., hal. 8

${ }^{24}$ Ibnu Miskawaih, op.cit., hal. 38-39 


\section{Tujuan Pendidikan Akhlak}

Ibnu Miskawaih mengatakan bahwa tujuan pendidikan akhlak adalah terwujudnya sikap batin yang mampu mendorong secara spontan untuk melahirkan semua perbuatan yang bernilai baik sehingga mencapai kesempurnaan dan memperoleh kebahagiaan yang sejati dan sempurna. Dalam Muhammad Yusuf Musa, Abuddin Nata bahwa persoalan al-sa'adat merupakan persoalan utama dan mendasar bagi kehidupan umat manusia dan sekaligus bagi pendidikan akhlak. Menurut M. Abdul Hak Ansari, alsa'adat merupakan konsep komprehensif yang di dalamnya terkandung unsur kebahagiaan (happiness), kemakmuran (prosperity), keberhasilan (success), kesempurnaan (perfection), kesenangan (blessedness), dan kecantikan (beautitude). Oleh karena itu tujuan pendidikan yang ingin dicapai oleh Ibnu Miskawaihadalah bersifat menyeluruh, yakni mencapai kebahagiaan hidup manusia dalam arti yang seluas-luasnya.

2. Kode Etik Pendidik Dan Peserta Didik

Menurut Ibnu Miskawaih, pendidik mempunyai tugas dan tanggung jawab untuk meluruskan peserta didik melalui ilmu rasional agar mereka dapat mencapai kebahagiaan intelektual dan untuk mengarahkan peserta didik pada disiplin-disiplin praktis dan aktifitas intelektual agar dapat mencapai kebahagiaan praktis.

Dari pernyataan tersebut dapat diketahui bahwa pandangan Ibnu Miskawaih tentang pendidik sesuai dengan pandangannya tentang dayajiwa yang ada dalam diri manusia dan pendidik mempunyai tugas dan tanggung jawab untuk mengembangkan ilmu yang bersifat rasional dan praktis tersebut, sehingga etika filsafat Ibnu Miskawaih dapat dikategorikan pada filsafat etika praktis dan teoritis. Pandangan Ibnu Miskawaih tentang pendidik diklasifikasikan menjadi dua, yaitu orang tua dan guru. Sementara itu, guru menurutnya ada dua, yaitu guru ideal mua'lim al-hakim dan guru biasa dengan persyaratan masing-masing.

Adapun pandanga Ibnu Miskawaih tentang kewajiban peserta didik adalah mencintai guru yang melebihi cintanya terhadap orang tua. Bahkan kecintaan peserta didik terhadap gurunya disamakan dengan cinta terhadap Tuhannya. Oleh karena itu, dalam interaksi edukatif antara guru dan murid harus didasarkan pada perasaan cinta kasih. Dengan adanya dasar semacam ini proses pembelajaran diharapkan berjalan sesuai dengan yang diharapkan.

3. Metode pendidikan

Metode yang dikemukakan Ibnu Miskawaih dalam upaya mencapai akhlak yang baik adalah pertama; kemauan yang bersungguh-sungguh. Adanya kemauan secara 
bersungguh-sungguh untuk berlatih secara terus menerus dan menahan diri (al-'adat wa aljihad) untuk memperoleh keutamaan dan kesopanan yang sebenarnya adalah sesuai dengan keutamaan jiwa. ${ }^{25}$ Latihanini bertujuan untuk menahan kemauan jiwa al-syabwaniyyat dan al ghadabiyyat. Latihan yang dilakukan antara lain adalah dengan makan dan minum yang tidak berlebihan yang membawa pada kerusakan tubuh. Sedangkan yang kedua; yakni menjadikan pengetahuan dan pengalaman orang lain sebagai cermin bagi dirinya, yaitu pengetahuan dan pengalaman berkenaan dengan hukum akhlak yang berlaku bagi sebab munculnya kebaikan dan keburukan bagi manusia.

Dengan cara ini seseorang tidak akan hanyut kepada perbuatan yang tidak baik, karena ia bercermin kepada perbuatan buruk dan akibat buruk yang dialami orang lain. ${ }^{26}$

4. Materi pendidikan akhlak

Secara garis besar Ibnu Miskawaih mengklsifikasikan materi pendidikan akhlak ke dalam tiga jenis, yaitu (1) hal-hal yang wajib bagi kebutuhan tubuh manusia, (2) halhal yang wajib bagi jiwa manusia dan (3) hal-hal yang wajib bagi hubungannya dengan sesama manusia. Pembagian semacam ini tidak terlepas dari pembagian Ibnu Miskawaih tentang daya jiwa manusia.

Dari ketiga pokok materi tersebut, maka akan diperoleh ilmu yang secara garis besar dapat dikelompokkan menjadi dua, pertama; ilmu-ilmu tentang pemikiran (al-ulum al-fikriyah), kedua; ilmu yang berkaitan dengan indera (al-ulum al-bissiyat). ${ }^{27}$

5. Lingkungan pendidikan.

Kebahagiaan tidak akan dapat dicapai oleh manusia tanpa bantuan orang lain, kebahagiaan bisa dicapai jika manusia bekerjasama, saling tolong menolong dan saling melengkapi. Kondisi tersebut akan tercipta jika sesama manusia saling mencintai.Menurut Ibnu Miskawaih sebaik-baik manusia adalah orang yang berbuat baik terhadap keluarga dan orang-orang yang masih ada kaitan dengannya; Walaupun Ibnu Miskawaih tidak membicarakan secara eksplisit tentang lingkungan pendidikan, tetapi ia banyak membicarakan tentang lingkungan masyarakat secara umum.

\section{Aktualisasi Pendidikan Akhlak}

Globalisasi telah menyebarkan arus informasi yang begitu banyak dan beragam. Dan arus informasi tersebut tidak hanya berupa pengetahuan tetapi juga berbagai nilai, dan nilai-nilai yang sepintas lalu terasa baru dan asing. Apakah nilai-nilai itu bersifat positif atau negatif

\footnotetext{
${ }^{25}$ Ibnu Maskawaih, op.cit., hal. 65

${ }^{26}$ Abuddin Nata, op.cit., hal. 23 - 25

${ }^{27}$ Ibnu Maskawaih, Kitab al-Sa'adat, hal. 54
} 
tergantung pada nilai-nilai budaya dan tradisi yang telah berlaku didalam masyarakat. Dan yang lebih penting lagi pengaruh globalisasi adalah pengaruh nilai-nilai seperti materialisme, konsumerisme, hedonisme, penggunaan kekerasan dan narkoba yang dapat merusak moral masyarakat. ${ }^{28}$

Dalam menghadapi globalisasi tersebut sebaiknya kita tidak boleh bersikap apriori menolak apa saja yang datang bersama arus globalisasi itu, misalnya dengan dalih itu semua adalah budaya dan nilai-nilai Barat yang bersifat negatif. Sebaliknya kita harus bersikap selektif dan berusaha menfilter nilai-nilai dan menanamkan nilai-nilai (akhlak) pada peserta didik agar dapat mempersiapkan mereka dalam menghadapi tantangan globalisasi yang mereka hadapi dan alami.

Dalam rangka penanaman nilai-nilai (akhlak) tersebut pendidikan menjadi kunci utama, tentu saja penanaman nilai-nilai tersebut tidak akan dapat diwujudkan bila ia hanya mengandalkan pendidikan formal semata, setiap sektor pendidikan lain baik formal, informal maupun non formal harus difungsikan secara integral. Di samping itu, pendidikan harus diarahkan secara seimbang antara aspek kognitif, afektif dan psikomotorik.

Pendidikan mempunyai peran penting dalam sosialisasi nilai-nilai (akhlak) kepada peserta didik, maka diperlukan sistem pendidikan yang bermutu dan sesuai dengan perkembangan zaman. Untuk itu diperlukan reformulasi terhadap pendidikan Islam, dimana pendidikan Islam harus bersifat seimbang antara tujuan yang bersifat duniawi dan ukhrawi serta yang tidak kalah pentingnya adalah diperlukan penanaman akhlak pada diri peserta didik. Penanaman akhlak kepada peserta didik ini harus seimbang antara akhlak yang berdimensi rasional (etika rasional) dan akhlak yang berdimensi religius murni (etika religus), sehingga hasil akhir pendidikan Islam diharapkan akan mampu mewujudkan pribadi-pribadi yang mempunya kecerdasan tinggi dan sikap religius yang mapan atau iman, ilmu dan amalnya berjalan secara seimbang.

\section{PENUTUP}

Bagian terpenting dalam kegiatan filosofis Ibn Miskawaih didedikasikan untuk etika. Ibn Miskawaih adalah seorang moralis dalam arti sebenarnya. Tiga buku yang terpenting dalam pembahasannya mengenai etika telahsampai pada masyarakat, yaitu: (1) Tartîb as-Sa'âdah, (2) Tahdzîb al-Akhlâq, dan (3) Jawi dan Khirad.

Manusia dalam pandangan Ibnu Miskawaih adalah makhluk yang mempunyai aktivitas yang khas, yang tidak dimiliki oleh makhluk lain yang ada pada bumi ini. Manusia merupakan benda

${ }^{28}$ Shindhunata, Menggagas Pendidikan Baru Pendidikan Demokratisasi, Otonomi, Civil Society Globalisasi, (Yogyakarta : Tiara Wacana, 2000), hal. $106-107$ 
alam yang paling mulia Ibnu Miskawaih menyebutkan bahwa manusia dipandang sebagai manusia sempurna karena dua hal yang dimilikinya, yaitu kognitif (teoritis) dan praktis.

Pemikiran Ibnu Miskawaih dalam hal pendidikan tidak bias dilepas dari konsepnya tentang manusia dan akhlak. Ibnu Miskawaih mengatakan bahwa tujuan pendidikan akhlak adalah terwujudnya sikap batin yang mampu mendorong secara spontan untuk melahirkan semua perbuatan yang bernilai baik sehingga mencapai kesempurnaan dan memperoleh kebahagiaan yang sejati dan sempurna.

\section{REFERENSI}

Abdullah,Taufik, et. al, Ensiklopedi Islam, Jakarta: PT. Ichtiar Baru Van Hoeve, 2000.

Azhar Basyir, Ahmad 1983. Miskawaib: Riwayat Hidup dan Pemikiran Filsafatnya. Yogyakarta: Nur Cahaya.

Fakhry, Majid. 1995. Etika Dalam Islam, terj. Zakiyuddin Baidhawy, Yogyakarta: Pustaka Pelajar. Kartono, Kartini, 1992. Pengantar Ilmu Mendidik Teoritis. Bandung: Mandar Maju.

Magniz Suseno,Franz. 1987. Etika Dasar: aslah-maslah pokok, filsafat moral, Yogyakarta: Kanasils.

Mahmud Subhi, Ahmad. 2001. Filsafat Etika; Tanggapan Kaum Rasionalis dan Intusionalis Islam. Jakarta: Serambi.

Majidi, Busyair. 1997. Konsep Penddikan Islam Para Filosof Muslim. Yogyakarta: al-Amin Press.

Miskawaih, Ibnu. 1994. Menuju Kesempurnaan Akblak, terj. Tabdrib al-Akblak. Bandung: MIZAN. , Tabdzib al-Akblak wa Tathbir al-A'araq. (Beirut: Mansyurah Dar al-Maktabah al-Hayat, $1398 \mathrm{H}$.

Nata, Abudin. 2003. Pemikiran Para Tokoh Pendidikan Islam, Seri Kajian FilsafatPendidikan Islam. Jakarta: Raja Grafindo Persada.

Shindhunata. 2000. Menggagas Pendidikan Baru Pendidikan Demokratisasi, Otonomi, Civil Society Globalisasi. Yogyakarta: Tiara Wacana.

Syarif, M. M. 1992. para filosof muslim. Bandung: Penerbit Mizan. 